Running head: Social perception predicts insight

\title{
Social perception predicts awareness of illness in persons with schizophrenia
}

Frida K. Feyer, $\mathrm{PsyD}^{1^{*}}$, Stein Andersson, $\mathrm{PhD}^{2}$, Camilla B. Büchmann, PsyD ${ }^{1,3}$, Ingrid Melle, $\mathrm{MD}, \mathrm{PhD}^{1,3}$, Ole A. Andreassen, $\mathrm{MD}, \mathrm{PhD}^{1,3}$, Anja Vaskinn, $\mathrm{PhD}^{1,3}$

Conflicts of Interest and Source of Funding: This work was supported by The South-Eastern Norway

Regional Health Authority (grant 2010007 and 2017069 to AV) and The Department of Psychology, University of Oslo, Norway (postdoctoral grant to AV). The authors declare no conflict of interest.

\footnotetext{
${ }^{1}$ Norwegian Centre for Mental Disorders Research, Oslo University Hospital, Ullevål Hospital, Building 49, Kirkeveien 166, 0450 Oslo, Norway

${ }^{2}$ Department of Psychology, University of Oslo, Forskningsveien 3A, 0373 Oslo, Norway

${ }^{3}$ Institute of Clinical Medicine, University of Oslo, Kirkeveien 166, 0450 Oslo, Norway

${ }^{*}$ Corresponding author: Frida K. Feyer, Norwegian Centre for Mental Disorders Research, Oslo University Hospital, Ullevål Hospital, Building 49, P.O. Box 4956 Nydalen 0424 Oslo, (+47)46541440, fridakf@mail.uio.no
} 


\begin{abstract}
Lack of clinical insight in patients with schizophrenia is an obstacle to optimal treatment. Social cognition is one of several variables central to insight deficits in schizophrenia. The aim of this study was to investigate clinical insight in relation to one domain of social cognition, social perception, while controlling for effects of non-social cognition and symptom severity. Clinical insight was measured in fifty-five patients with schizophrenia or schizoaffective disorder, using the Birchwood Insight Scale. Relationships across Domains was used to assess Social Perception. Social perception predicted one of three subscales of clinical insight; "Awareness of illness", and was the only unique contributor to this subscale. This indicates that social perception is linked to clinical insight through awareness of illness. More research is needed to fully understand the relationship between social and non-social cognition and symptoms in relation to clinical insight.
\end{abstract}

Keywords: social cognition, social perception, clinical insight, awareness of illness, schizophrenia, psychosis, self-report 


\section{Introduction}

In psychotic disorders, clinical insight refers to the realization that one is suffering from a mental illness and to the ability to relabel certain experiences as pathological (David, 1990). Clinical insight has been divided into three independent subdomains; awareness of illness (the understanding that strange and distressing experiences are due to an unspecific illness), relabeling of symptoms (the ability to identify and distinguish specific psychotic symptoms) and awareness of need for treatment (seeing treatment as a solution to distressing experiences) (David, 1990). Impaired clinical insight contributes to poor treatment adherence (Novick et al., 2015), worse functional outcome (Segarra et al., 2012), and reduced quality of life (Boyer et al., 2012). Although some studies have found a paradoxical effect, where improved clinical insight was related to reduced hope, self-esteem and quality of life (HassanOhayon et al., 2009), this association may occur through self-stigma (Hassan-Ohayon, 2012), suggesting that it is not improved insight in itself that leads to poor outcomes. Poor clinical insight in schizophrenia has been associated with psychotic symptoms, coping style, and cognitive functioning, including social cognition (Cooke et al., 2007; Chan et al., 2012; Clark et al., 2018; Sapara et al., 2015). A recent appraisal of the current state of the art (David, 2019) points out that insight involves metacognition, i.e. reflecting upon one's own cognition. The term metacognition is not used uniformly within the psychopathology literature, but broadly refers to "thinking about thinking" (Moritz \& Lysaker, 2018). And indeed, studies have found associations between insight and metacognition (Vohs et al., 2015; Lysaker et al., 2019). Integrative models have been proposed, where poor insight is seen as multi-determined by above-mentioned factors such as psychotic symptoms, stigma, neurocognition, metacognition and social cognition (Lysaker et al., 2018; Vohs et al., 2016). Metacognitive processes in insight involve trying to see one's own thinking and behavior through someone 
else's eyes before comparing it to a representation of mental health (David, 2019), implying the relevance of social cognition to clinical insight.

Social cognition refers to mental operations that underlie social interactions (Green et al., 2008) and is divided into different subdomains. Among these, both theory of mind (Bora et al., 2007; Zhang et al., 2016), emotion perception (Pijnenborg et al., 2013; Vaskinn et al., 2013) and attributional style (Langdon et al., 2006) have shown low to moderate associations with clinical insight. A few studies have examined the relative contribution of several social cognitive domains to clinical insight. Béland and Lepage (2017), found that affective empathy, the ability to tune in on and respond to the emotions of others (but not theory of mind and emotion perception) was a significant predictor of clinical insight, also after controlling for general cognitive performance, negative symptoms, and antipsychotic dosage. Another study found that empathy, emotion perception and social perception all were significantly associated with clinical insight, but only empathy and emotion recognition were significant predictors of clinical insight in multiple linear regression analyses (Bhagyavathi, Mehta, \& Thirthalli, 2014). These findings suggest that the ability to process social information is related to the ability to make self-judgments, including whether one has a psychotic illness.

To our knowledge, the study by Bhagyavathi et al (2014) is the only one that has investigated how social perception relates to clinical insight. Although social perception was not the strongest social cognitive contributor to clinical insight in that study, it may in fact be of particular interest to clinical insight. Social perception refers to the ability to make inferences and form impressions of others from cues and rules in social interactions. This is in contrast to other social cognitive domains that are largely based on information from a single individual, i.e. decisions about one person's intentions or beliefs (theory of mind) or emotional expressions (emotion perception). Social perception may therefore be hypothesized to 
contribute to clinical insight due to their shared focus on social context. Thoughts and behaviors can only be considered as psychotic in a social context, because they are defined as pathological through deviations from other's experiences of the world. Someone with a psychotic illness who is able to make correct inferences about social contexts, i.e. who has intact social perception, can be hypothesized to also be able to notice that his/her thoughts and behaviors deviate from what is normal in that social context. This in turn may contribute to better clinical insight. Although other social cognitive domains have been shown to predict clinical insight, much of the variance in clinical insight is still unexplained. Social perception is therefore an interesting concept to investigate in relation to clinical insight.

The aim of this study is to examine whether social perception predicts clinical insight in individuals with schizophrenia, when the effect of symptom severity and non-social cognition is simultaneously taken into account.

\section{Methods}

\section{$\underline{\text { Participants }}$}

Fifty-five individuals with schizophrenia $(n=45)$ or schizoaffective disorder $(n=10)$, recruited from hospitals in the Oslo area, participated in the Thematically Organized Psychosis (TOP) research study at the Norwegian Centre for Mental Disorders Research (NORMENT) at Oslo University Hospital. Exclusion criteria were history of neurological injury or disease, IQ $<70$, and age below 18 years or above 55 years (for demographics and clinical characteristics, see Table 1). Clinical assessments were done by trained clinical psychologists, medical doctors or psychiatrists, whereas the cognitive assessments were undertaken by clinical psychologists trained by a specialist in clinical neuropsychology. The participants received oral and written information before providing their informed consent. The Regional Committee for Medical Research Ethics and the Norwegian Data Inspectorate approved the study. 


\section{$\underline{\text { Instruments }}$}

Clinical insight was measured using the Norwegian version (Jónsdóttir et al., 2008) of the Birchwood Insight Scale (IS) (Birchwood et al., 1994). This is an eight-item self-report questionnaire, with items organized into three domains; awareness of illness, awareness of need for treatment and relabeling of symptoms. Psychometric properties have been found to be satisfactory, both for the original (Birchwood et al., 1994) and translated (Buchmann et al., 2018) version.

Social perception was assessed with the abbreviated Norwegian version (Vaskinn, Fiske, \& Green, 2017) of the Relationships across Domains (RAD) test (Sergi et al., 2009). RAD measures relationship perception, an aspect of social perception that pertains to recognizing rules and norms used by others in organizing social interactions. Relationship perception is based on Fiske's (1991) theory of relational models, which states that four models of social interaction govern how individuals organize their relationships. These are communal sharing (characterized by equality, warm emotions and sharing), authority ranking (hierarchical organization with a decision maker and a follower), equality matching (reciprocity as organizing principle, 50/50 sharing) and market pricing (focused on proportionality and value). RAD consists of short vignettes describing the interpersonal behaviors of a man and a woman. This dyadic relationship is consistent with one of four relational models. By answering three questions for each vignette, it can be established if the participant has implicit knowledge of relational models, i.e. relationship perception (Sergi et al., 2009).

Non-social cognition was measured using the MATRICS Consensus Cognitive Battery (MCCB) (Nuechterlein et al., 2008), excluding the social cognitive subtest. Clinical symptom severity was measured with the Positive and Negative Syndrome Scale (PANSS) (Kay, Fiszbein, \& Opler, 1987), using a validated five-factor model, containing the factors positive, 
negative, disorganized, excited and depressed. (e.g. Wallwork et al., 2012). For clinical symptoms and cognition in participants, see Table 2.

\section{$\underline{\text { Statistical Methods }}$}

All statistical analyses were performed using IBM Statistical Package for the Social Sciences 25 for Windows. Two-tailed tests were applied for all statistical tests. Based on analyses of sample distributions and tests of normality, parametric tests were chosen. In order to investigate if social perception was associated with clinical insight, bivariate Pearson correlations were conducted. Correlations between the three subscales and total scale of IS and RAD, MCCB and the five factor scores of PANSS were investigated (Table 3). Significance level was adjusted using the Bonferroni correction (for seven analyses i.e. plevel $=0.05 / 7=0.007)$. For the insight measures that showed medium-sized associations $(r>$ 0.30 cf. Cohen, 1988) with RAD, hierarchical multiple regression analyses were undertaken. IS was entered as the dependent variable with MCCB, RAD and PANSS factors entered as independent variables. MCCB and PANSS factors were only entered if they showed at least medium-sized associations with the insight measure in the initial bivariate correlational analyses. Independent variables were entered in the following order: in the first block, nonsocial cognition, based on the assumption that non-social cognition is the basic foundation for higher-order abilities such as social cognition; followed by social cognition in the second block, and clinical symptoms in the third block, due to its clearer state-like character.

\section{Results}

IS Awareness of illness was moderately associated with RAD $(\mathrm{r}=0.37), \mathrm{MCCB}(\mathrm{r}=0.33)$ and PANSS Disorganized factor $(\mathrm{r}=0.40)$, and only the IS Awareness of illness association with RAD reached the corrected level of statistical significance $(p=0.007)$. Therefore, a threeblock hierarchical multiple regression analysis was conducted with Awareness of illness as the 
dependent variable (see Table 4) and MCCB, RAD and PANSS Disorganized as independent variables. In block one, MCCB contributed significantly to the regression model $\left(\mathrm{F}_{(1,53)}=\right.$ $6.316, \mathrm{p}<0.05)$ accounting for $10.6 \%$ of variance in awareness of illness. $R A D$, entered in Block 2, explained an additional $7.8 \%$ of variation, with total explained variance $18.4 \%$, and a significant $\mathrm{R}^{2}$ change $\left(\mathrm{R}^{2}\right.$ Change $\left.=0.078 ; \mathrm{F}_{(1,52)}=4.953 ; \mathrm{p}<0.05\right)$. Finally, PANSS Disorganized entered in Block 3 did not yield a significant increase in explained variation $\left(\mathrm{R}^{2}\right.$ Change $\left.=0.056 ; \mathrm{F}_{(1,51)}=3.772 ; \mathrm{p}=0.058\right)$, but it increased the amount of variance explained from $18.4 \%$ to $24 \%\left(\mathrm{~F}_{(3,51)}=5.379, \mathrm{p}<0.005\right)$. Taken together, only RAD had a unique and significant contribution to IS Awareness of illness in the final model.

\section{Discussion}

This study found that social perception was significantly associated with one domain of clinical insight; awareness of illness. Social perception, as measured by the RAD, was a stronger predictor of awareness of illness than non-social cognition and symptom severity. Conceptualizing clinical insight as three separate subdomains, each of the three subdomains can be affected or not affected, independently of each other (David, 1990). Awareness of need for treatment entails an understanding of distressing experiences as treatable, but does not require an understanding that one's distressing experiences differ markedly from those of others. Relabeling of symptoms presupposes an understanding that certain distressing experiences are unique compared to other experiences, but does not require an understanding that these experiences are markedly different from the experiences of other people. However, in order to possess awareness of illness, it is necessary to be able to see how one's own experiences differ from those of others in order to recognize that one suffers from a disease. Social perception may play a key role in this aspect of clinical insight as it involves making inferences and forming impressions about social situations and others through an understanding of social rules and cues. Impaired social perception may make it harder to 
identify discrepancies between one's own experiences and actions, and those of others. This, in turn, will hinder the use of the social context to identify that one suffers from a disease that causes distressing and deviating experiences.

Disorganized symptoms did not give an individually significant contribution, but it increased the amount of variance explained from $18.4 \%$ to $24 \%$. A possible reason for this is that disorganized symptoms may overlap with executive function (e.g. Kravariti et al., 2005) which has been found to correlate with clinical insight (Chan et al., 2012). However, effects of non-social cognition were not significant after social perception was entered in the statistical model. Since executive function may be related to clinical insight, one could have expected a significant effect of non-social cognition. The lack of such an association may be due to the battery used. The MCCB battery does not provide an elaborate evaluation of executive function (Holmén et al., 2012). Exploratory analyses of the relation between MCCB subtests and awareness of illness revealed bivariate correlations spanning from 0.01 to 0.42 . The correlation coefficient between the executive subtest, NAB Mazes, and awareness of illness was 0.21, while working memory had the strongest correlation (WMS-III, 0.42). Since working memory has been found to be strongly associated with executive function in schizophrenia (e.g. Gold et al, 2018; McGurk et al, 2004), it is perhaps not surprising that working memory was strongly associated with clinical insight. Future research should investigate how executive function might influence the link between social cognition and clinical insight, by using a more elaborate evaluation of executive function.

A limitation of the present study is the lack of other social cognitive measures. Since we only investigated social perception, we are unable to say whether social perception could be a better predictor of awareness of illness than other social cognitive domains.

\section{Conclusions}


This study showed that social perception was linked to awareness of illness and that is was a stronger predictor than clinical symptoms and non-social cognition. This suggests that interventions improving social perception could contribute to better insight, and consequently even to improved functioning. Few existing interventions for schizophrenia target social perception (Javed \& Charles, 2018). We suggest that more studies are needed to confirm the important role of social perception in schizophrenia.

\section{References}

Béland, S., \& Lepage, M. (2017). The relative contributions of social cognition and selfreflectiveness to clinical insight in enduring schizophrenia. Psychiatry Research, 258(Supplement C), 116-123. doi:https://doi.org/10.1016/j.psychres.2017.09.082

Bhagyavathi, H., Mehta, U., \& Thirthalli, J. (2014). The relationship between empathy, emotion processing and clinical insight in remitted schizophrenia patients. European Archives of Psychiatry and Clinical Neuroscience, 264(6), 551-553. doi:10.1007/s00406-013-0484-2

Birchwood, M., Smith, J., Drury, V., Healy, J., Macmillan, F., \& Slade, M. (1994). A self-report Insight Scale for psychosis: reliability, validity and sensitivity to change. Acta psychiatrica Scandinavica, 89(1), 62. https://doi.org/10.1111/j.1600-0447.1994.tb01487.x

Bora, E., Sehitoglu, G., Aslier, M., Atabay, I., \& Veznedaroglu, B. (2007). Theory of mind and unawareness of illness in schizophrenia. European Archives of Psychiatry and Clinical Neuroscience, 257(2), 104-111. doi:10.1007/s00406-006-0681-3

Boyer, L., Aghababian, V., Richieri, R., Loundou, A., Padovani, R., Simeoni, M. C., Lançon, C. (2012). Insight into illness, neurocognition and quality of life in schizophrenia. Progress in Neuro-Psychopharmacology and Biological Psychiatry, 36(2), 271-276. doi:http://dx.doi.org/10.1016/j.pnpbp.2011.10.008 
Buchmann, C., Pedersen, G., Aminoff, Sr., Laskemoen, J., Meile, I., \& Lagerberg, T. V. (2018). Good Psychometric Properties of the Birchwood Insight Scale for Patients with Bipolar Disorder. Early Interv. Psychiatry, 12(s1), 153-153.

Chan, S. K. W., Chan, K. K. S., Lam, M. M. L., Chiu, C. P. Y., Hui, C. L. M., Wong, G. H. Y., Chen, E. Y. H. (2012). Clinical and cognitive correlates of insight in first-episode schizophrenia. Schizophrenia Research, 135(1-3), 40-45. doi:10.1016/j.schres.2011.12.013

Clark, S. V., Mittal, V. A., Bernard, J. A., Ahmadi, A., King, T. Z., \& Turner, J. A. (2018). Stronger default mode network connectivity is associated with poorer clinical insight in youth at ultrahigh-risk for psychotic disorders. Schizophrenia Research, 193, 244-250. doi:10.1016/j.schres.2017.06.043

Cohen, J. (1988). Statistical power analysis for the behavioral sciences (2nd ed.). Hillsdale, N. J: Laurence Erlbaum.

Cooke, M., Peters, E., Fannon, D., Anilkumar, A. P. P., Aasen, I., Kuipers, E., \& Kumari, V. (2007). Insight, distress and coping styles in schizophrenia. Schizophrenia Research, 94(1-3), 12-22. doi:10.1016/j.schres.2007.04.030

David, A. S. (2019). Insight and psychosis: the next 30 years. The British Journal of Psychiatry, 1-3.

David, A. (1990). Insight and Psychosis. British Journal of Psychiatry, 156(6), 798-808. doi:10.1192/bjp.156.6.798

Fiske, A. P. (1991). Structures of social life: The four elementary forms of human relations: Communal sharing, authority ranking, equality matching, market pricing. New York, NY, US: Free Press.

Green, M. F., David L. Penn, Richard Bentall, William T. Carpenter, Wolfgang Gaebel, Ruben C. Gur, Ann M. Kring, Sohee Park, Steven M. Silverstein, Robert Heinssen, (2008) Social 
Cognition in Schizophrenia: A NIMH Workshop on Definitions, Assessment, and Research Opportunities, Schizophrenia Bulletin, Volume 34, Issue 6, Pages 1211-1220, https://doi.org/10.1093/schbul/sbm145

Gold, J. M., Robinson, B., Leonard, C. J., Hahn, B., Chen, S., McMahon, R. P., \& Luck, S. J. (2018). Selective attention, working memory, and executive function as potential independent sources of cognitive dysfunction in schizophrenia. Schizophrenia bulletin, 44(6), 1227-1234.

Hasson-Ohayon, I., Ehrlich-Ben Or, S., Vahab, K., Amiaz, R., Weiser, M., \& Roe, D. (2012). Insight into mental illness and self-stigma: The mediating role of shame proneness. Psychiatry Research, 200(2-3), 802-806.

Hasson-Ohayon, I., Kravetz, S., Meir, T., Rozencwaig S. (2009) Insight into severe mental illness, hope, and quality of life of persons with schizophrenia and schizoaffective disorder, Psychiatry Research, 167 (3) (2009), pp. 231-238

Holmén, A., Juuhl-Langseth, M., Thormodsen, R., Sundet, K., Melle, I., \& Rund, B. R. (2012). Executive function tests in early-onset psychosis: which one to choose? Scandinavian Journal of Psychology, 53(3), 200-205. doi:10.1111/j.1467-9450.2012.00940.x

Javed, A., \& Charles, A. (2018). The Importance of Social Cognition in Improving Functional Outcomes in Schizophrenia. Frontiers in psychiatry, 9, 157-157. doi:10.3389/fpsyt.2018.00157

Jónsdóttir, A. H., Engh, A. J., Friis, A. S., Birkenæs, A. A., Ringen, A. P., Vaskinn, A. A., Andreassen, A. O. (2008). Measurement of Insight in Patients with Bipolar Disorder: Are Self-Rated Scales Developed for Patients with Schizophrenia Applicable? The Journal of Nervous and Mental Disease, 196(4), 333-335. doi:10.1097/NMD.0b013e31816a62b2

Kay, S. R., Fiszbein, A., \& Opler, L. A. (1987). The Positive and Negative Syndrome Scale (PANSS) for Schizophrenia. Schizophrenia Bulletin, 13(2), 261-276. doi:10.1093/schbul/13.2.261 
Kravariti, E., Dixon, T., Frith, C., Murray, R., \& McGuire, P. (2005). Association of symptoms and executive function in schizophrenia and bipolar disorder. Schizophrenia Research, 74(2), 221231. doi:https://doi.org/10.1016/j.schres.2004.06.008

Langdon, R., Corner, T., McLaren, J., Ward, P. B., \& Coltheart, M. (2006). Externalizing and personalizing biases in persecutory delusions: The relationship with poor insight and theoryof-mind. Behaviour Research and Therapy, 44(5), 699-713. doi:10.1016/j.brat.2005.03.012

Larøi, F., Barr, W. B., \& Keefe, R. S. E. (2004). Neuropsychology of Insight in Psychiatric and Neurological Disorders. In X. F. Amador \& A. S. David (Eds.), Insight and psychosis: awareness of illness in schizophrenia and related disorders (2nd ed.). Oxford: Oxford University Press.

Lera, G., Herrero, N., González, J., Aguilar, E., Sanjuán, J., \& Leal, C. (2011). Insight among psychotic patients with auditory hallucinations. Journal of clinical psychology, 67(7), 701. doi:10.1002/jclp.20799

Lysaker, P.H., Pattison, M.L., Leonhardt, B.L., Phelps, S. and Vohs, J.L. (2018), Insight in schizophrenia spectrum disorders: relationship with behavior, mood and perceived quality of life, underlying causes and emerging treatments. World Psychiatry, 17: 12-23. doi:10.1002/wps.20508

Lysaker, P. H., Gagen, E., Wright, A., Vohs, J. L., Kukla, M., Yanos, P. T., \& Hasson-Ohayon, I. (2018). Metacognitive deficits predict impaired insight in schizophrenia across symptom profiles: a latent class analysis. Schizophrenia bulletin, 45(1), 48-56.

McGurk, S. R., Coleman, T., Harvey, P. D., Reichenberg, A., White, L., Friedman, J., \& Davis, K. L. (2004). Working memory performance in poor outcome schizophrenia: relationship to age and executive functioning. Journal of Clinical and Experimental Neuropsychology, 26(2), 153-160. 
Moritz, S., \& Lysaker, P. H. (2018). Metacognition Research in Psychosis: Uncovering and Adjusting the Prisms That Distort Subjective Reality. Schizophrenia Bulletin, Volume 45, Issue 1, January 2019, Pages 17-18, https://doi.org/10.1093/schbul/sby151

Novick, D., Montgomery, W., Treuer, T., Aguado, J., Kraemer, S., \& Haro, J. M. (2015). Relationship of insight with medication adherence and the impact on outcomes in patients with schizophrenia and bipolar disorder: results from a 1-year European outpatient observational study. BMC psychiatry, 15(1), 189.

Nuechterlein, K., Green, M., Kern, R., Baade, L., Barch, D., Cohen, J. Marder, S. (2008). The MATRICS Consensus Cognitive Battery, Part 1: Test Selection, Reliability, and Validity. The American journal of psychiatry, 165(2), 203-213. doi:10.1176/appi.ajp.2007.07010042

Pijnenborg, G. H. M., Spikman, J. M., Jeronimus, B. F., \& Aleman, A. (2013). Insight in schizophrenia: associations with empathy. European Archives of Psychiatry and Clinical Neuroscience, 263(4), 299-307. doi:10.1007/s00406-012-0373-0

Sapara, A., Ffytche, D. H., Cooke, M. A., Williams, S. C. R., \& Kumari, V. (2015). Is it me? Verbal self-monitoring neural network and clinical insight in schizophrenia. Psychiatry Research: Neuroimaging, 234(3), 328-335. doi:10.1016/j.pscychresns.2015.10.007

Segarra, R., Ojeda, N., Pena, J., Garcia, J., Rodriguez-Morales, A., Ruiz, I. \& Gutierrez, M. (2012). Longitudinal changes of insight in first episode psychosis and its relation to clinical symptoms, treatment adherence and global functioning: one-year follow-up from the Eiffel study. European Psychiatry, 27(1), 43-49.

Sergi, M. J., Fiske, A. P., Horan, W. P., Kern, R. S., Kee, K. S., Subotnik, K. L., Green, M. F. (2009). Development of a measure of relationship perception in schizophrenia. Psychiatry Research, 166(1), 54-62. doi:http://dx.doi.org/10.1016/j.psychres.2008.03.010 
Vaskinn, A., Lovgren, A., Egeland, M. K., Feyer, F. K., Ostefjells, T., Andreassen, O. A., Sundet, K. (2019). A randomized controlled trial of training of affect recognition (TAR) in schizophrenia shows lasting effects for theory of mind. Eur Arch Psychiatry Clin Neurosci. doi:10.1007/s00406-019-00997-z

Vaskinn, A., Fiske, A. P., \& Green, M. F. (2017). Enhancing tolerability of a measure of social perception in schizophrenia: comparison of short and long Norwegian versions of the Relationships across Domains test. Cognitive Neuropsychiatry, 22(3), 254-262. doi:10.1080/13546805.2017.1307174

Vaskinn, A. A., Sundet, A. K., Ueland, A. T., Agartz, A. I., Melle, A. I., \& Andreassen, A. O. (2013). Social Cognition and Clinical Insight in Schizophrenia and Bipolar Disorder. The Journal of Nervous and Mental Disease, 201(6), 445-451. doi:10.1097/NMD.0b013e31829480c8

Jenifer L. Vohs, Sunita George, Bethany L. Leonhardt \& Paul H. Lysaker (2016) An integrative model of the impairments in insight in schizophrenia: emerging research on causal factors and treatments, Expert Review of Neurotherapeutics, 16:10, 1193-1204, DOI: 10.1080/14737175.2016.1199275

Vohs, J., George, S., Leonhardt, B., \& Lysaker, P. (2016). An integrative model of the impairments in insight in schizophrenia: Emerging research on causal factors and treatments. Expert Review of Neurotherapeutics, 16(10), 1193-1204.

Vohs, J. L., Lysaker, P. H., Liffick, E., Francis, M. M., Leonhardt, B. L., James, A., \& Breier, A. (2015). Metacognitive capacity as a predictor of insight in first-episode psychosis. The Journal of nervous and mental disease, 203(5), 372-378.

Wallwork, R. S., Fortgang, R., Hashimoto, R., Weinberger, D. R., \& Dickinson, D. (2012). Searching for a consensus five-factor model of the Positive and Negative Syndrome Scale for schizophrenia. Schizophrenia Research, 137(1-3), 246-250. doi:10.1016/j.schres.2012.01.031 
Zhang, Q., Li, X., Parker, G. J., Hong, X.-H., Wang, Y., Lui, S. S. Y., Chan, R. C. K. (2016). Theory of mind correlates with clinical insight but not cognitive insight in patients with schizophrenia. Psychiatry Research, 237, 188-195. doi:10.1016/j.psychres.2016.01.044 
Table 1: Demographic and clinical characteristics

Mean (SD)

Age $\quad 29.9(8.6)$

Sex (males/females) $\quad 38 / 17$

WASI IQ $\quad 101.7(13.0)$

Education (years) $\quad 12.5(2.6)$

Illness duration (years) ${ }^{\mathrm{a}} \quad 7.9(7.8)$

GAF-f $\quad 44.2(10.6)$

GAF-s $\quad 44.1(11.6)$

${ }^{a}=1$ missing.

WASI $=$ Wechsler Abbreviated Scale of Intelligence, GAF- $\mathrm{f}=$ Global Assessment of Functioning function, GAF-s = Global Assessment of Functioning symptoms 
Table 2: Clinical symptoms and cognition in participants with schizophrenia $(n=55)$

\begin{tabular}{|c|c|c|c|c|c|}
\hline & & Mean & $\mathrm{SD}$ & Min & Max \\
\hline RAD Short Total: & & 24.8 & 4.72 & 14.0 & 35.0 \\
\hline \multirow{2}{*}{\multicolumn{6}{|c|}{$\begin{array}{l}\text { Birchwood Insight } \\
\text { Scale: }\end{array}$}} \\
\hline & & & & & \\
\hline & Total score & 8.0 & 2.0 & 4.0 & 12.0 \\
\hline & Awareness of Illness & 2.5 & 0.9 & 0.5 & 4.0 \\
\hline & Relabeling of symptoms & 2.7 & 0.8 & 1.0 & 4.0 \\
\hline & Need for Treatment & 2.8 & 0.8 & 0.0 & 4.0 \\
\hline
\end{tabular}

PANSS:

$\begin{array}{lrrrr}\text { Positive factor } & 10.2 & 4.0 & 4.0 & 20.0 \\ \text { Negative factor } & 13.4 & 5.4 & 6.0 & 26.0 \\ \text { Disorganized factor } & 5.8 & 2.6 & 3.0 & 12.0 \\ \text { Excited factor } & 5.4 & 1.8 & 4.0 & 11.0 \\ \text { Depressed factor } & 7.8 & 2.9 & 3.0 & 14.0 \\ & 40.8 & 7.5 & 25.8 & 55.1\end{array}$

MCCB T-score:

$\begin{array}{llll}40.8 & 7.5 & 25.8 & 55.1\end{array}$

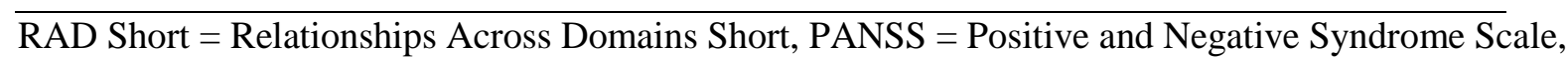
MCCB $=$ MATRICS Cognitive Consensus Battery 
Table 3: Bivariate correlation analyses (Pearson's r) between Birchwood Insight Scale and RAD Short, MCCB total and the PANSS Subscales

\begin{tabular}{lcccc}
\hline & \multicolumn{3}{c}{ Birchwood Insight Scale } \\
\cline { 2 - 5 } & Total score & Awareness of illness & Relabeling of symptoms & Need for treatment \\
\hline RAD short & 0.25 & $0.37^{* *}$ & 0.13 & 0.08 \\
MCCB total & $0.30^{*}$ & $0.33^{*}$ & 0.27 & 0.14 \\
PANSS positive & $-0.30^{*}$ & $-0.27^{*}$ & $-0.27^{*}$ & $-0.19^{*}$ \\
PANSS negative & -0.14 & -0.17 & -0.11 & -0.10 \\
PANSS disorganized & $-0.41^{* *}$ & $-0.40^{* *}$ & $-0.44^{* *}$ & -0.16 \\
PANSS excited & -0.07 & -0.22 & -0.22 & 0.05 \\
PANSS depressed & 0.17 & 0.10 & 0.26 & 0.09 \\
\hline * = significant at the 0.05 level. (2-tailed) & $* *=$ significant at the corrected alpha level $\mathrm{p}<0.007$ (2-tailed).RAD \\
short = Relationships across domains, MCCB total = MATRICS Cognitive Consensus Battery, PANSS = \\
Positive and Negative Syndrome Scale
\end{tabular}


Table 4: Hierarchical multiple regression model for Birchwood Awareness of Illness $(\mathrm{N}=$ 55)

\begin{tabular}{|c|c|c|c|c|c|c|c|c|}
\hline & $\beta$ & Partial & Sig. & $\mathrm{R}^{2}$ & $\mathrm{R}^{2}$ change & $F(d f)$ & F change & Sig. of F change \\
\hline Block 1 & & & & 0.106 & - & $6.316(1,53)$ & 6.316 & $0.015^{*}$ \\
\hline MCCB total & $0.33 *$ & 0.33 & 0.015 & & & & & \\
\hline Block 2 & & & & 0.184 & 0.078 & $5.870(2,52)$ & 4.953 & $0.030 *$ \\
\hline MCCB total & 0.23 & 0.24 & 0.083 & & & & & \\
\hline RAD Short & $0.29 *$ & 0.30 & 0.030 & & & & & \\
\hline Block 3 & & & & 0.240 & 0.056 & $5.379(3,51)$ & 3.772 & 0.058 \\
\hline MCCB total & 0.09 & 0.08 & 0.570 & & & & & \\
\hline RAD Short & $0.27 *$ & 0.28 & 0.045 & & & & & \\
\hline PANSS Disorganized & -0.29 & -0.26 & 0.058 & & & & & \\
\hline
\end{tabular}

$*$ = significant at the 0.05 level. $* *=$ significant at the 0.01 level.

RAD short $=$ Relationships across domains, MCCB total = MATRICS Cognitive Consensus Battery, PANSS = Positive and Negative Syndrome Scale 